\title{
A integração do PNAE com o PRONAF: OPORTUNIDADES E DESAFIOS
}

\section{The integration of PNAE and PRONAF: opportunities and challenges}

RESUMO A agricultura familiar (AF) resistiu como forma de vida de miIhares de homens e mulheres ao longo do tempo. Isto porque, apesar do constante avanço do agronegócio, a AF conseguiu se manter como fonte alternativa à violência no campo, êxodo rural, precarização das relações sociais, de emprego e gênero no meio rural, causados por esse modelo agroexportador. Desde 1954 e com a posterior criação da Lei n. ${ }^{\circ} 11.947$, de junho de 2009, o Programa Nacional de Alimentação Escolar (PNAE) é posto como mais uma alternativa de mercado para os agricultores familiares comercializarem os seus produtos. O trabalho trata de uma análise das oportunidades e desafios existentes na interação entre o PNAE e a AF. A partir de pesquisa bibliográfica e de entrevistas semiestruturadas com gestores do PNAE, a pesquisa revelou que essa interação enfrenta dois grandes desafios: como conseguir expandir a aquisição de alimentos para os modelos de gestão adotados no PNAE, e como estreitar a relação entre profissionais do PNAE e agricultores familiares. O presente trabalho revela que, dentre as potencialidades, destaca-se principalmente, o desenvolvimento local, melhora na qualidade vida dos agricultores familiares e melhoria na qualidade dos alimentos fornecidos.

Palavras-chave: Merenda Escolar. Programa Nacional de AliMENTAÇÃo Escolar. Programa NACIONAL de FortaleCIMENTO dA AGRICULTURA FAMILIAR.

ABSTRACT Family farming (FF) has resisted as the way of life of thousands of men and women over time. Despite the constant advance of agribusiness, FF has been able to remain as an alternative source to rural violence, rural exodus, precariousness social relations, employment and gender in rural areas, caused by this agroexport model. Since 1954, with law n. ${ }^{0} 11.947$, of june 2009, the National School Feeding Program (PFSN) is set as another market alternative for family farmers to market their products. The paper deals with an analysis of the opportunities and challenges that exist in the interaction between the PFSN and the FF. Based on bibliographic research and semi-structured interviews with PNAE managers, the research revealed that this interaction faces two major challenges, how to expand food acquisition to the management models adopted in the PFSN and how to strengthen the relationship between PFSN professionals and family farmers. The present study reveals the potentialities, the local development, the improvement in the quality of life of the family farmers and the improvement in the quality of the food supplied.

KeYWORDS: SCHOOL LUNCH. NATIONAL SCHOOL FEEDING PROGRAM. National PRogram to StREnGthen FAmily AGRICULtURE.

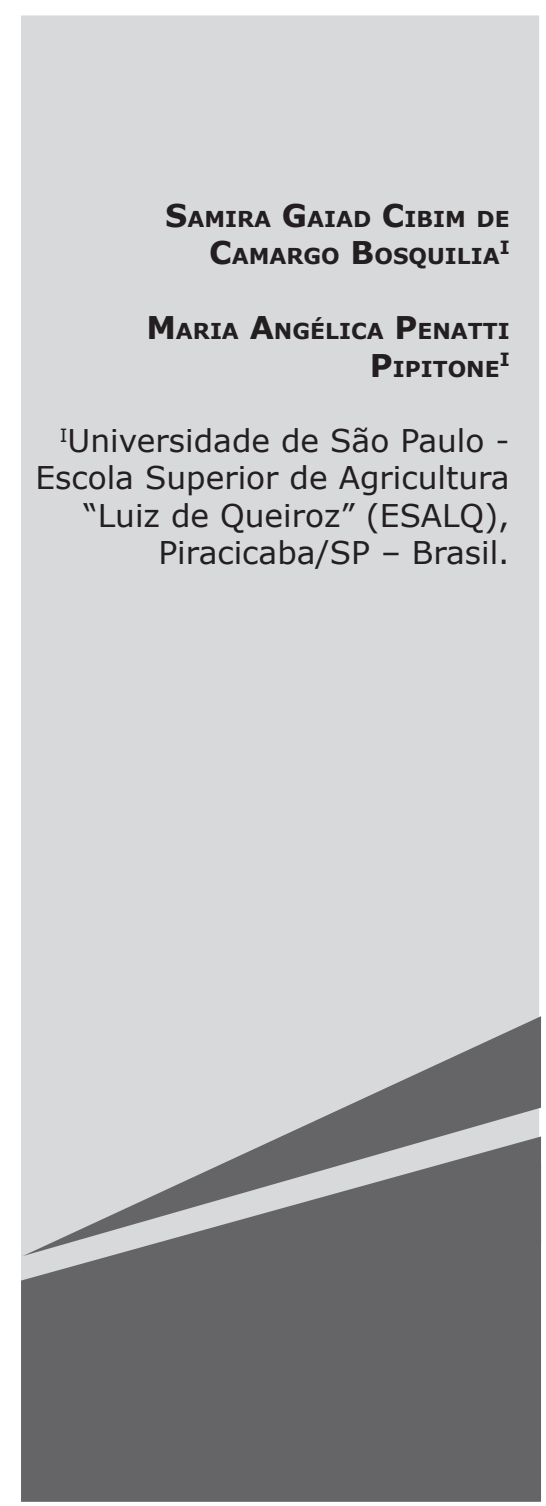




\section{INTRODUÇÃO}

A alimentação é um dos fatores essenciais para a manutenção da vida na Terra e faz parte da rotina diária da humanidade. No contexto escolar, a alimentação assume papel fundamental no processo de socialização e desenvolvimento das crianças e jovens e, neste sentido, é possível observar um crescente aumento das preocupações por parte de organismos internacionais e nacionais, ligados à área da saúde e educação, em promover o desenvolvimento de atividades promotoras da saúde no ambiente escolar (COSTA et al. 2001).

Desde o surgimento da Carta de Ottawa, em 1986, durante a primeira Conferência Internacional sobre Promoção da Saúde, a promoção da saúde é definida como um processo de capacitação da população para atuar na melhoria da sua qualidade de vida e saúde e o alcance de um estado completo de bem-estar físico, mental e social, e se baseia na capacidade dos indivíduos e grupos saberem identificar aspirações, satisfazer necessidades e modificar favoravelmente o meio ambiente, inclusive e essencialmente por meio da garantia da alimentação em quantidade e qualidade suficiente (BUSS, 2003).

Além disso, o direito à alimentação é considerado um direito humano que está incluído no Pacto Internacional dos Direitos Econômicos, Sociais e Culturais, postulado em 1966, posteriormente à Declaração Universal dos Direitos Humanos; esta, por sua vez, foi assinada em dezembro de 1948, pelos povos do mundo, por intermédio de seus chefes de Estado e governos.

Face o exposto, é notável a importância da alimentação para o desenvolvimento de uma vida com qualidade, principalmente na infância e adolescência. Para Camossa et al. (2005), é na infância e adolescência que se constituem hábitos adequados e saudáveis, uma vez que, a criança e o adolescente tornam-se sujeitos autônomos e aptos para realizar suas escolhas alimentares de forma saudável e condizente com suas necessidades fisiológicas, psicológicas e sociais.
Neste sentido, o Programa Nacional de Alimentação Escolar (PNAE), pode ser considerado um espaço ou instrumento pedagógico, pois além de ser um programa fornecedor de alimentos, constitui um espaço educativo, por exemplo, quando estimula a integração de temas relativos à nutrição e à merenda ao currículo escolar (COSTA et al. 2001).

Em corolário ao avanço cientifico nas áreas correlatas à alimentação, alimentação escolar e segurança alimentar e nutricional, o Programa apontou a oportuna interface de ações integradoras entre a alimentação escolar e agricultura familiar.

A agricultura familiar passou a interagir com o PNAE a partir da instituição da Lei Federal n.o 11.947, de 16 de junho de 2009, que definiu que do total dos recursos financeiros repassados pelo Fundo Nacional de Desenvolvimento da Educação (FNDE), para o desenvolvimento do PNAE, no mínimo 30\% deveriam ser utilizados na aquisição de gêneros alimentícios provenientes da agricultura familiar.

Por ser uma instituição e interação recente, o presente artigo pode colaborar no desenvolvimento do tema e na geração de informações que auxiliem em um maior entendimento dos processos relacionados a essas questões e a importância das mesmas para a sustentabilidade local.

Diante dessa afirmação, este trabalho tem por objetivo analisar as oportunidades e desafios existentes da interação entre o Programa Nacional de Alimentação Escolar e a agricultura familiar com vistas à sustentabilidade de ambos.

A fim de atender de maneira satisfatória aos objetivos antes enunciados, este artigo foi estruturado da seguinte maneira: de início são apresentados e discutidos a nível conceitual, preceitos relativos ao Programa Nacional de Alimentação Escolar, Agricultura Familiar e Programa Nacional de Fortalecimento da Agricultura Familiar. Estas abordagens têm a expectativa de proporcionar elementos conceituais para melhor fundamentar as digressões realizadas no presente trabalho. No item seguinte são apresentados os procedimentos 
metodológicos, com uma breve descrição dos dados utilizados e das entrevistas que foram conduzidas, e nos tópicos finais os resultados e conclusões, com destaque para questões relacionadas ao Programa Nacional de Alimentação Escolar e Agricultura Familiar e aos principais avanços e oportunidades existentes da vinculação dos mesmos.

\section{Programa nacional de AlimentaçÃo ESCOLAR (PNAE)}

Em 2013, o Programa Mundial de Alimentos ( $\left.P M A^{1}\right)$ lançou um relatório sobre o "Estado de Alimentação Escolar no Mundo", que ofereceu uma análise global da situação dos programas de alimentação escolar tanto em países em desenvolvimento como em países desenvolvidos, além de revelar como os países utilizam a merenda escolar como uma 'rede de proteção" em tempos de crise (WFP, 2013). O relatório destacou a necessidade de encontrar meios para melhorar a eficácia e eficiência dos programas já implementados, além de apontar para o fato de a cobertura dos programas de alimentação escolar ser menor em países onde há maior ocorrência de problemas relacionados à escassez de alimentos (Tabela 1).

Tabela 1 - Países com maior número de beneficiários da Alimentação Escolar no Mundo.

\begin{tabular}{ll}
\hline País & Cobertura (milhões) \\
\hline Índia & 114 \\
Brasil & 47 \\
Estados Unidos & 45 \\
China & 26 \\
\hline
\end{tabular}

Fonte: WFP - World Food Programme, (2013).

\footnotetext{
Com início em 1963, constitui-se a maior agência humanitária do mundo que fornece em média a cada ano alimentos a 90 milhões de pessoas em 80 países, incluindo 58 milhões de crianças. O PMA é a filial de auxílio alimentar da Organização das Nações Unidas e busca ajudar pessoas incapazes de produzir ou obter alimento suficiente para si e para suas famílias.
}

Os primeiros ensaios sobre alimentação escolar no Brasil datam da década de 30 , do século XX. Inicialmente, as questões alimentares resumiam-se aos problemas de abastecimento e fiscalização de alimentos. A partir de 1930 surgiram os estudos do médico e nutrólogo brasileiro Josué de Castro, que alertou para os problemas alimentares existentes e até então desconhecidos pela sociedade brasileira, e buscou reforçar o papel do Estado na atenção com a alimentação pública (ACUÑA e THOMAZ, 2003). Em 1945, ocorreu a criação de inúmeros órgãos e entidades no campo da alimentação, entre eles o Conselho Nacional de Alimentação, que vigorou até o ano de 1972.

O ano de 1954 marcou o surgimento do Programa Nacional de Alimentação Escolar no Brasil, que inicialmente possuía um gerenciamento centralizado. Porém, em 1994 o gerenciamento passou a ser descentralizado por meio da Lei $n .^{\circ} 8.913$, de 12 de julho de 1994, que preconizou o convênio com os municípios, enquanto as secretarias de educação dos Estados e do Distrito Federal se responsabilizaram pelo atendimento dos alunos dos municípios que não aderiram à descentralização.

Por descentralização no âmbito das políticas públicas se entende uma melhor racionalização da logística, dos custos de distribuição e uma maior participação da sociedade na gestão da política por meio da criação de Conselhos participativos. No caso do PNAE, a descentralização contribuiu para o respeito à cultura alimentar da população nas diferentes localidades do país e permitiu a inserção de pais de alunos, professores, membros da comunidade nos processos decisórios da gestão do PNAE, por meio da criação dos Conselhos Municipais de Alimentação Escolar.

No ano de 1998, houve a instituição do Conselho de Alimentação Escolar (CAE) em cada município brasileiro, como órgão deliberativo, fiscalizador e de assessoramento, com a importante função de fiscalizar a aplicação dos recursos destinados ao PNAE, bem como, acompanhar o programa nas unidades escolares, na elaboração dos cardápios e na progra- 
mação, execução e avaliação do atendimento (PIPITONE et al. 2003).

Um novidade ocorreu na gestão do PNAE quando, em 2009, ficou estabelecido que do total de recursos financeiros repassados pelo FNDE, no mínimo 30\% deveriam ser utilizados na aquisição de gêneros alimentícios produzidos por agricultores familiares e empreendedores familiares rurais, detentores da Declaração de Aptidão ao Programa Nacional de Fortalecimento da Agricultura Familiar - DAP Física e/ou Jurídica, conforme a Lei da Agricultura Familiar n. ${ }^{\circ} 11.326$, de 24 de julho de 2006, e enquadrados no Programa Nacional de Fortalecimento da Agricultura Familiar - PRONAF.

No município de Piracicaba, localidade da realização da pesquisa, o PNAE teve início formal em 1958, e no ano de 1984, o município passou a fazer parte das cidades que optaram pela municipalização do Programa da Merenda Escolar por meio do Decreto estadual n. ${ }^{\circ}$ 22.379, de 19/6/1984.

A partir disto, a prefeitura municipal passou a ser responsável pela prestação de serviços, aquisição de gêneros alimentícios, preparo e distribuição de merenda aos alunos do ensino fundamental das escolas estaduais e municipais que ofereciam ensino gratuito, vinculados à rede de ensino durante o ano letivo e férias escolares. Dentre os benefícios da municipalização, pode-se citar a introdução de produtos “in natura”, que geraram variações e maior aceitabilidade dos cardápios, além do respeito aos hábitos alimentares e da cultura local dos beneficiários.

Desde 2009 a Divisão de Alimentação e Nutrição (DAN) executa o Programa de Alimentação Escolar por meio de dois sistemas, autogestão e terceirizado.

$\mathrm{Na}$ autogestão, a DAN é inteiramente responsável pela execução do programa, cabendo a seus técnicos a aquisição de todos os itens utilizados nas cozinhas (utensílios, equipamentos, gêneros alimentícios, gás, equipamentos de proteção individual, produtos de limpeza etc.), a distribuição das refeições e também a contratação e qualifi- cação de mão de obra, por meio de concurso público.

No sistema terceirizado, por sua vez, a contratação da empresa acontece por meio de licitação pública. Uma vez contratada, a empresa ficará responsável pelo pré-preparo, preparo e distribuição da alimentação escolar. Neste sistema, cabe à DAN apenas a fiscalização do cumprimento do contrato por meio de visitas periódicas nas unidades escolares.

O município de Piracicaba, segundo dados oficiais, atende a um total de 218 instituições de ensino, das quais 82 escolas atendidas pertencem à educação infantil, mais 21 instituições conveniadas e pelo modelo de gestão terceirizada, são atendidas 59 escolas estaduais, 46 municipais, 7 Centro de Atendimento Sócio-Educativo (CASE) (parceria), 2 Escolas Técnicas Estaduais de São Paulo (Etec) e 1 Educação de Jovens e Adultos/Serviço Social da Indústria (EJA/SESI) (PIRACICABA, 2016a).

\section{Agricultura familiar e Programa NACIONAL DE FORTALECIMENTO DA AGRI- CULTURA FAMILIAR (PRONAF)}

A agricultura familiar caracteriza-se como a forma de vida de milhares de homens e mulheres que, ao longo do tempo, vêm resistindo ao processo excludente e altamente competitivo do mercado agrícola, com a atuação dos empreendimentos que atuam na logística do agronegócio (SILVA e JESUS, 2010).

Pode-se dizer que o conceito de agricultura familiar segue duas referências em destaque, a compreendida e elaborada pelo Instituto Nacional de Colonização da Reforma Agrária - INCRA e o Fundo das Nações Unidas para Agricultura e Alimentação - FAO (1996) e o modelo proposto por Hughes Lamarche (MARQUES, 2004).

A primeira corrente de pensamento proposta pela FAO/INCRA define o conceito a partir de três características centrais. Primeiro, que a gestão da unidade produtiva e os investimentos nela realizados são feitos por indivíduos que mantêm entre si laços de sangue ou 
de casamento, segundo, que a maior parte do trabalho é igualmente fornecida pelos membros da família e terceiro, que a propriedade dos meios de produção pertence à família e é em seu interior que se realiza sua transmissão em caso de morte ou de aposentadoria dos responsáveis pela unidade produtiva.

Diante disto, é notável que o eixo central da diferença da agricultura familiar e a agricultura patronal reside no fato de que na agricultura familiar o trabalho assalariado não é o predominante, existindo uma relação diferenciada entre terra, trabalho e família e propriedade e preservação da vida.

A segunda corrente de pensamento coordenada por Lamarche (1993), utiliza a heterogeneidade como a principal explicação da presença e resistência da agricultura familiar. Segundo o autor, é possível conceber tipologia que permite identificar formas e organização das unidades de produção, tomando sobretudo em conta, graus de relação com o mercado. Neste contexto, dois modelos foram caracterizados, o original e o ideal.

O modelo original corresponde aos clássicos traços de camponês, onde as necessidades de consumo e a organização produtiva é muito forte. No modelo ideal, por sua vez, fica a caracterização da total integração à economia de mercado. O afastamento desses dois extremos seria a solução mais adequada para a reprodução da agricultura familiar, sendo assim, revela-se que a as unidades familiares possuem uma excepcional capacidade de adaptação (MARQUES, 2004).

No Brasil, a expressão agricultura familiar é recente e emergiu no contexto brasileiro a partir de meados da década de 1990, período que ficou marcado pela tentativa de fortalecimento da mesma. Nesta época, as políticas públicas de incentivo à agricultura familiar se fortaleceram e deram novos rumos ao desenvolvimento rural brasileiro, onde se destaca o PRONAF.

O PRONAF, assim, surgiu como um mecanismo de atendimento a uma antiga reivindicação das organizações dos trabalhadores rurais, que por meio de lutas e organizações, buscavam uma política social e econômica direcionada especificamente para o desenvolvimento rural, depois de se sentirem prejudicados pela abertura comercial da economia. (FERNANDES, 2013).

As Jornadas Nacionais da Luta, organizadas pela CONTAG (Confederação Nacional dos Trabalhadores na Agricultura), CUT Rural (Central Única dos Trabalhadores) e MST (Movimento dos Sem Terra), caracterizaram-se como movimentos sociais de extrema importância no início de 1990, pelas lutas e reivindicações expostas por meio das jornadas e que posteriormente ganharam novos contornos e passaram a ser denominadas de "Grito da Terra Brasil", tendo a busca por políticas para a agricultura a sua principal demanda (MATTEI, 2005).

Tais movimentos e organizações tiveram papel fundamental na legitimação do PRONAF, pois a partir deles houve o reconhecimento da agricultura familiar como uma nova categoria social pelo Estado, que até então era designada como agricultura de pequenos produtores, agricultores de subsistência etc.

Além disso, de acordo com o Decreto 1.946, de 28 de junho de 1996, o PRONAF tem por objetivo a promoção do desenvolvimento sustentável no segmento rural constituído pelos agricultores familiares, de modo a propiciar-lhes o aumento da capacidade produtiva, a geração de empregos e a melhoria da renda.

Sendo assim, o PRONAF pode ser apontado como uma ferramenta do fortalecimento da agricultura familiar, pois proporciona a inserção produtiva de um elevado número de famílias em situação de pobreza no campo, tornando as famílias menos dependentes de programas de transferência de renda, além de fortalecer a capacidade produtiva dos agricultores familiares por meio da geração de mais empregos e do aumento da renda nas áreas rurais, o que, por conseguinte, melhora a qualidade de vida do produtor rural e sua família. 


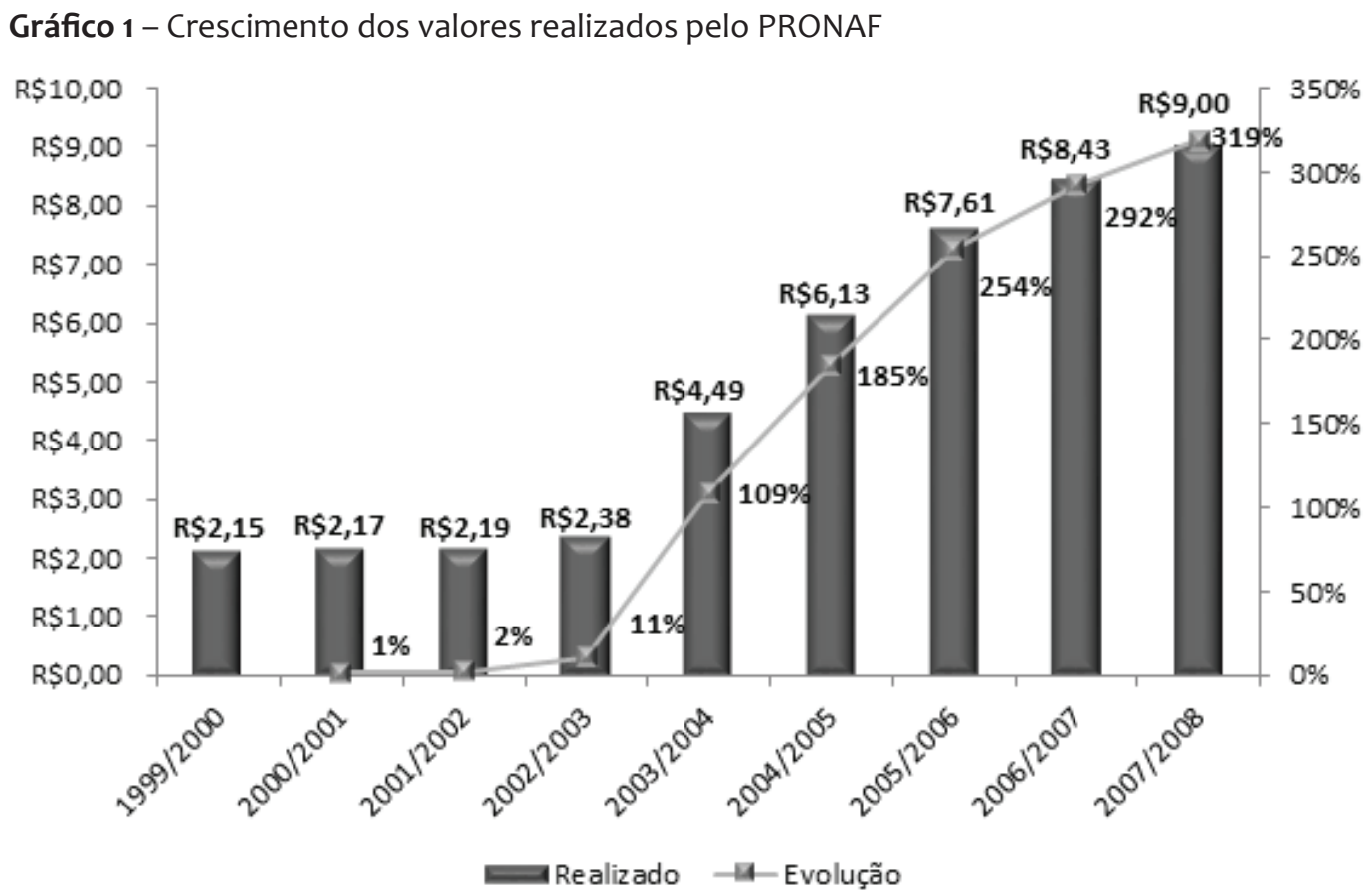

Fonte: BRASIL (2015)

A partir do Gráfico 1, é possível verificar que a utilização dos recursos do PRONAF não atinge 100\% da capacidade no período de 1999 - 2008, ou seja, a disponibilidade de crédito no período citado foi maior que o aproveitamento dos mesmos pelos produtores aptos a utilizá-los, no entanto, é notável que o uso de tais recursos vem crescendo ano a ano, o que sugere que os produtores estão investindo mais em suas produções, gerando maior qualidade e aumento de renda e consolidando os objetivos do programa.

\section{Procedimentos dA PESQUISA}

Com o objetivo de analisar as interações, as oportunidades e os desafios existentes a partir da integração promovida entre o Programa Nacional de Alimentação Escolar e o Programa Nacional de Fortalecimento da Agricultura Familiar, foram coletados dados a partir de pesquisa bibliográfica e de entrevistas semiestruturadas. A análise dos dados, por sua vez, ocorreu por meio de análise documental e análise do conteúdo das entrevistas.
A metodologia de pesquisa realizada com técnicas responsáveis pelos setores técnicos relacionados com o PNAE e o PRONAF no município de Piracicaba utilizou dados de fontes primárias, secundárias e entrevistas semiestruturadas com técnicos chaves da cadeia, sendo esta última aplicada toda vez que há interesse ou necessidade de se obter dados e/ou informações mais detalhadas para compreender a dinâmica do objeto de análise.

A escolha do município para a pesquisa recaiu sobre Piracicaba (SP), por ser considerada um importante polo de agricultura, o que confere benefícios à produção e também pelo fato de o município possuir um já consolidado Programa de Alimentação Escolar em nível municipal.

Deste modo, neste trabalho foram realizadas entrevistas com uma gestora da área da alimentação escolar, que representa o Programa Nacional de Alimentar Escolar de Piracicaba (SP) e um professor doutor especialista em extensão rural e cooperativismo com larga experiência na assistência técnica 
e organização de produtores rurais da região de município, além de atuar extraoficialmente como agente de intermediação dos mesmos com facilitação das condições prévias de documentação para ocorrência da parceria entre o PRONAF e PNAE no âmbito local/municipal.

$O$ desenvolvimento do trabalho se deu no município de Piracicaba (SP), que conta com um Serviço de Alimentação Escolar, que abrange 218 escolas de educação básica e atende cerca de 85.415 escolares. O programa ganhou novos contornos durante sua trajetória histórica e atualmente encontra-se municipalizado, já que após a promulgação do decreto número 22.379, de 19 de junho de 1984, a Secretaria Estadual de Educação passou a conceder subvenção anual às prefeituras que aderiram ao projeto e Piracicaba passou a ser responsável pela prestação de serviços, aquisição de gêneros alimentícios, preparo e distribuição de merenda aos alunos do ensino fundamental das escolas estaduais, municipais e particulares que ofereciam ensino gratuito, vinculados à rede de ensino durante o ano letivo e férias escolares (PIRACICABA, 2016b).

Além do Programa Nacional de Alimentação Escolar, o município conta com a presença atuante do Conselho de Alimentação Escolar que, desde o ano 2000, vem exercendo seu papel de órgão fiscalizador do Programa Nacional de Alimentação Escolar.

\section{RESULTADOS E DISCUSSÃO}

O município de Piracicaba (SP) possui enorme potencial para a produção agrícola, isto porque, $90 \%$ de seu território é composto por área rural, sendo metade dele submetido ao cultivo de cana-de-açúcar e metade à pastagem e criação de gado. A área urbana do município representa os 10\% restantes, na qual um cinturão produtivo a delimita, ou seja, em torno de toda a zona urbana do município, há produtores, principalmente de gêneros folhosos, milho, mandioca e banana (PECORARI, 2006).

De acordo com dados da Prefeitura, em Piracicaba atualmente existem 290 agricultores familiares, sendo que 45 destes atuam nos
28 Varejões Municipais, ${ }^{2}$ além disso, a maioria destas famílias se dedica à produção de olerícolas (verduras e legumes), frutas (banana, laranja e manga) e na fabricação de queijos (PIRACICABA, 2016b).

Esses agricultores são responsáveis pela comercialização mensal de mais ou menos 1.000 toneladas de hortifrutigranjeiros, o que corresponde a cerca de $25 \%$ do volume comercializado nos 28 Varejões Municipais, distribuídos na área central e em diversos bairros do município.

Além dos Varejões Municipais como forma de escoamento da produção dos agricultores familiares, outro grande passo para a promoção da agricultura familiar está relacionado ao PNAE. Como já foi mencionado, o PNAE foi criado em 1954 e tem como objetivo principal contribuir para o desenvolvimento, a aprendizagem e o rendimento escolar dos estudantes, por meio do fornecimento regular de uma alimentação saudável compatível com a faixa etária dos escolares e distribuída durante a jornada escolar diária.

Presente nos municípios brasileiros, $\mathrm{O}$ PNAE historicamente sempre apoiou a agricultura familiar ao comprar alimentos para a alimentação escolar. No entanto, somente após a instauração da Lei n. ${ }^{\circ} 11.947$, de 16 de junho de 2009 (que estipulou que no mínimo $30 \%$ da verba federal repassada pelo Fundo Nacional de Desenvolvimento da Educação (FNDE) deveriam ser destinados à aquisição de gêneros alimentícios originários da agricultura familiar) é que se criou um elo institucional entre a alimentação escolar e a agricultura familiar local ou regional (SOUZA-ESQUERDO e BERGAMASCO, 2014).

E para os agricultores familiares poderem participar dessa interação com o PNAE (via Chamadas Públicas) e usufruir dos créditos do PRONAF, eles precisam buscar o sindi-

\footnotetext{
Foram criados em agosto de 1982 em Piracicaba com objetivo de melhorar o abastecimento alimentar em Piracicaba, cabendo a eles um melhor escoamento da produção de alimentos, colocando o produtor rural em contato direto com o consumidor final, uma vez que o Mercado Municipal e as Feiras Livres já não supriam as necessidades do município.
} 
cato rural, a empresa ou serviço de Assistência Técnica e Extensão Rural (ATER) mais próxima para obtenção da Declaração de Aptidão ao Pronaf (DAP), que será emitida de acordo com a renda anual e as atividades desenvolvidas, direcionando, assim, o agricultor familiar para as linhas de crédito específicas a que ele tem direito. Para os beneficiários de reforma agrária e do crédito fundiário, o processo é praticamente o mesmo, exceto por terem de procurar o Instituto Nacional de Colonização e Reforma Agrária (INCRA) ou a Unidade Técnica Estadual (UTE) para adquirirem sua Declaração de Aptidão ao Pronaf (DAP).

Uma vez que todos os requisitos tenham sido preenchidos, a prefeitura fica incumbida da ampla divulgação das Chamadas Públicas e do oferecimento das informações necessárias às organizações da agricultura familiar que se interessem em fornecer produtos para a alimentação escolar, designando critérios como o gênero, período, local de entrega, quantidade e padrão de qualidade (MULLER, 2010).

Os aspectos positivos da interação do PNAE com a agricultura familiar são inúmeros, dentre eles, destaca-se a capacidade de fortalecimento da sustentabilidade econômica e social no âmbito local e regional, devido ao potencial de acesso a um novo espaço de comercialização dos produtos dos agricultores familiares e da garantia de qualidade dos alimentos oferecidos aos escolares.

Há contribuição também para a promoção de empregos e trabalho no meio rural, ocasionando a diminuição do êxodo rural e a consequente diminuição da pobreza rural, uma vez que o PNAE, ao adquirir produtos de agricultores locais, constituiria uma nova fatia de mercado para os agricultores familiares.

No caso, no município de Piracicaba, o Programa de Alimentação Escolar atualmente obtém $41,43 \%$ de seus alimentos oriundos de agricultura familiar, sendo eles, suco natural de laranja, iogurte, queijo muçarela, leite integral e hortaliças (BRASIL, 2015).

No entanto, um desafio à cadeia da alimentação escolar em Piracicaba seria o de fomentar a aquisição de alimentos de agri- cultores familiares locais e regionais para ambos os modelos de gestão da alimentação escolar, isto por que, atualmente, ainda há entraves e desafios a serem enfrentados nesta questão, principalmente em relação à gestão terceirizada.

O sistema de autogestão também requer a ampliação de esforços de todos os envolvidos para que cada vez seja maior a participação de agricultores familiares na alimentação escolar, ainda que já seja perceptível a existência de uma maior facilidade de interação entre os atores envolvidos na operacionalização, uma vez que a merenda escolar servida é totalmente elaborada pelas merendeiras do município, o que contribui para uma maior fiscalização e facilidade de aquisição de gêneros alimentícios de agricultores familiares via Chamada Pública.

Contudo, a pesquisa demonstrou também que o agricultor familiar precisa saber se planejar, pois em período de férias escolares, por exemplo, o PNAE não realiza compras para a merenda escolar. Sendo assim, o agricultor familiar precisa saber descobrir outros mercados, ainda que consiga escoar sua produção na maior parte do ano letivo.

Outra questão abordada durante a pesquisa foi o incentivo à formação de associações e cooperativas por parte dos agricultores familiares, para que assim eles possam ser capazes de tornar seus produtos competitivos. No caso do PNAE de Piracicaba, eles somente realizam compras de agricultores familiares cooperados ou associados, pois o agricultor familiar que produz sozinho normalmente possui entraves técnicos e logísticos que impossibilitam que eles possam realizar parcerias com o Programa de Alimentação Escolar.

Por fim, segundo o professor doutor entrevistado, especialista em extensão rural e cooperativismo, para melhorar e aumentar a participação dos agricultores familiares vinculados ao PRONAF e que fornecem gêneros alimentícios ao PNAE, foi constatada a necessidade de maior envolvimento dos profissionais de nutrição atuantes no serviço municipal de 
merenda escolar com os produtores. Isto seria importante para melhorar a comunicação entre os gestores das duas políticas, promoveria um consenso logístico e de formas de produção, além de estreitar objetivos e metas em comum, e também evitar pequenos desgastes oriundos da pequena ou inexistente comunicação que há entre os setores.

Outro aspecto apontado na pesquisa seria a possibilidade da criação de uma linha específica no PRONAF, correspondente apenas à organização dos agricultores familiares que quiser realizar parceria com o PNAE. Essa linha de investimento faria que a ligação entre os dois programas fosse organizada de uma maneira mais eficiente para ambos os programas públicos, além de esclarecer muitas dúvidas técnicas e operacionais por parte dos agricultores familiares que desejam escoar seus produtos para o PNAE.

A criação dessa possível linha de crédito no PRONAF também facilitaria a simples tomada de conhecimento por parte dos agricultores familiares, que muitas vezes desconhecem essa possibilidade de parceria.

\section{CONSIDERAÇÕES FINAIS}

Diante das análises obtidas com a pesquisa, foi possível concluir que existem dois grandes desafios postos para a ampliação da participação dos agricultores familiares na alimentação escolar do município de Piracicaba, sendo um deles o desafio de como conseguir expandir cada vez mais a aquisição de alimentos oriundos da agricultura familiar para a autogestão e como iniciar e avançar com essa aquisição para a gestão terceirizada, que atualmente ainda se encontra à revelia das diretrizes da Lei n. ${ }^{\circ} 11.947$, de 16 de junho de 2009. Outro desafio seria o fato de haver muita dificuldade de envolvimento entre os profissionais de nutrição atuantes na DAN do município e os agricultores locais, visto que a falta de comunicação entre tais protagonistas pode dificultar a manutenção e a criação de novos contratos via Chamada Pública.

Porém, evidencia-se que apesar dos desafios inerentes à gestão de quaisquer políticas públicas, a interação entre PNAE e agricultores familiares, por intermédio do PRONAF, possui enorme potencial de crescimento para todos os envolvidos, já que a busca pela obtenção de alimentos dos agricultores familiares inseridos nestas regiões, além de fomentar a economia local, indiretamente contribui para a melhora na qualidade de vida dos agricultores familiares e beneficia a segurança alimentar e nutricional dos escolares.

Os estudantes contemplados pelo PNAE também se beneficiam do fornecimento de alimentos oriundos da agricultura familiar, pois além de quase sempre serem constituídos a partir de métodos sustentáveis de produção, os alimentos tornam o cardápio mais diversificado e evidencia-se um maior frescor e qualidade dos alimentos destinados.

\section{REFERÊNCIAS}

ACUÑA, K.; THOMAZ, C. "Surgimento da Ciência da Nutrição e breve histórico das políticas de alimentação no Brasil”. Revista Baiana de Saúde Pública, Salvador, v. 27, n. 1/2, p. 114-123. 2003. BRASIL. MDA - Ministério do Desenvolvimento Agrário. Relatórios para Brasil e Semiárido, Regiões, Estados, Territórios e Municípios. 2015. Disponível em: http://www.mda.gov.br/sitemda/ pagina/acompanhe-a\%C3\%A7\%C3\%B5es-do-mda-e-incra. Acesso em: 16 mar. 2015.

BUSS, P. "Uma introdução ao conceito de promoção da saúde". In: CZERESNIA, D., FREITAS, C.M. Promoção da saúde: conceitos, reflexões, tendências. Rio de Janeiro: Fiocruz, 2003. CAMOSSA, A.C.A.; COSTA, F.N.A.; OLIVEIRA, P.F.; FIGUEIREDO, T.P. “Educação nutricional: uma área em desenvolvimento". Revista Alimentação e Nutrição, Araraquara, v. 16, n. 4, p. 349-354. 2005. COSTA, E.Q., RIBEIRO, V.M.B., RIBEIRO, E.C.O. "Programa de Alimentação Escolar: Espaço de Aprendizagem e Produção de Conhecimento”. Revista de Nutrição, Campinas, v. 14, n. 3, p. 225-229. 2001. 
DENARDI, R.A. "Agricultura familiar e políticas públicas: alguns dilemas e desafios para o desenvolvimento rural sustentável”. Revista de Agroecologia e Desenvolvimento Rural Sustentável, Porto Alegre, v. 2, n. 3, p. 56-62, jul.-set. 2001.

FERNANDES, A.M.S. "O Pronaf na agricultura familiar: sua criação, distribuição e principais resultados". 2013. 58f. Trabalho de Conclusão de Curso. Universidade Federal do Rio Grande do Sul, Porto Alegre.

LAMARCHE, H. Agricultura Familiar: comparação internacional. Campinas: Unicamp, 1993. MARQUES, P.E.M. “Concepções concorrentes em torno das políticas públicas de apoio à agricultura familiar: uma releitura sobre a construção do PRONAF". Disponível em: http://www. sober.org.br/palestra/12/060347.pdf. Acesso em: 16 mar. 2004.

MATTEI. L. Impactos do PRONAF: análise de indicadores. Brasília: MDA/NEAD, 2005.

MULLER, A. L. Programa de Aquisição de Alimentos da Agricultura Familiar e Programa Nacional de Alimentação Escolar. Brasília: Relatório de Consultoria, 2010.

PECORARI, R.C.F. "Uma proposta de inovação no cardápio escolar baseada na avaliação do programa de alimentação escolar, de Piracicaba - SP”. 2006. 165f. Dissertação (Mestrado em Ciências Alimentos e Nutrição). Universidade Estadual Júlio de Mesquita Filho, Araraquara.

PIPITONE, M.A.P.; OMETTO, A.M.H.; SILVA, M.V.; STURION, G.L.; FURTUOSO, M.C.O.; OETTERER, M. "Atuação dos conselhos municipais de alimentação escolar na gestão do programa nacional de alimentação escolar”. Revista de Nutrição, Campinas, v. 16, n. 2, p. 143-154. 2003.

PIRACICABA. PREFEITURA MUNICIPAL DE PIRACICABA. Agricultura familiar é modelo de produção para 290 famílias em Piracicaba. 2016a. Disponível em: http://www.piracicaba.sp.gov.br/ agricultura+familiar+e+modelo+de+producao+para+290+familias+em+piracicaba.aspx. Acesso em: 16 mar. 2016.

PIRACICABA. SECRETARIA MUNICIPAL DE EDUCAÇÃO DE PIRACICABA. Merenda Escolar. 2016b. Disponível em: http://www.educacao.piracicaba.sp.gov.br/site/merenda-escolar.html. Acesso em: 16 mar. 2016.

SILVA, J.R; JESUS, P. "Os desafios do novo rural e as perspectivas da agricultura familiar no Brasil”. Disponível em: http://connepi.ifal.edu.br/ocs/index.php/connepi/CONNEPI2010/paper/ viewFile/1407/4. Acesso em: 16 mar. 2010.

SOUZA-ESQUERDO, V.F.; BERGAMASCO, S.M.P.P. (2014) "Análise sobre o acesso aos programas de políticas públicas da agricultura familiar nos municípios do circuito das frutas (SP)". Revista de Economia e Sociologia Rural, Brasília, v. 52, n. 1, p. 205-222. 2014.

WFP - WORLD FOOD PROGRAMME. State of School Feeding WorldWide. 2013. Disponível em: http://www.wfp.org/content/state-school-feeding-worldwide-2013. Acesso em: 16 mar. 2013.

\section{Dados das Autoras}

\section{SAMIRA GAIAD CIBIM DE CAMARGO BOSQUILIA}

Doutoranda no Programa Interunidades de Pós-Graduação em Ecologia Aplicada da Universidade de São Paulo. Piracicaba/SP - Brasil.samira_gaiad@hotmail.com

\section{MARIA ANGÉLICA PENATTI PIPITONE}

Doutora em Educação pela Universidade Estadual de Campinas. Professora livre docente da Universidade de São Paulo. Piracicaba/SP - Brasil. angelicapenatti@gmail.com

Submetido em: 16-03-2017

Aceito em: 05-06-2017 